\title{
The Role of Honey Production in Economic Growth: Evidence from a Panel of Major Global Producers
}

\author{
Nicholas Apergis ${ }^{1}$, Sofia Eleftheriou ${ }^{2}$ \\ ${ }^{1}$ Department of Banking and Financial Management, University of Piraeus, Piraeus, Greece \\ ${ }^{2}$ Department of Business Administration, University of Piraeus, Piraeus, Greece
}

Email address:

napergis@unipi.gr (N. Apergis), Sofia.eleftheriou@unipi.gr (S. Eleftheriou)

\section{To cite this article:}

Nicholas Apergis, Sofia Eleftheriou. The Role of Honey Production in Economic Growth: Evidence from a Panel of Major Global Producers. International Journal of Agricultural Economics. Vol. 2, No. 5, 2017, pp. 154-159. doi: 10.11648/j.ijae.20170205.13

Received: August 4, 2017; Accepted: September 1, 2017; Published: October 12, 2017

\begin{abstract}
This paper investigates the contribution of honey production to economic growth. Considering a sample of the major honey producers coming from the Americas, Eastern and European groups, as well as by taking advantage of panel methodological approaches, the empirical analysis documents that honey production could serve as an engine of growth. The results also highlight that the honey industry seems to stronger contribute to economic growth in the case of the Eastern group followed by the Americas and European groups.
\end{abstract}

Keywords: Honey Production, Economic Growth, Major Global Honey Producers, Panel Data

\section{Introduction}

Agriculture plays a significant role in a sense that it can generate job opportunities, support rural development, and secure food production (Rephann, 2008). Overall, investment in agriculture is important for economic growth. Lack of investments in rural communities is a main reason for the chronic poverty in such rural areas (Duncan, 2005), while agricultural growth benefits the urban poor by reducing food prices (Byerlee, 2000). In addition, urbanization and its associated policies may decrease agricultural and other rural lands, thus, hindering agricultural production and environmental qualities (Rosenberger et al., 2002). Increasing the value of the product generated by agricultural enterprises through the construction of new linkages with markets, strengthens the rural agricultural economy (Banks and Marsden, 2000). Intensifying the research activity on the role of agricultural in the economic growth process is substantially crucial, because it helps to form both domestic and international policy decisions in relevance to how scarce resources are allocated to agricultural research and infrastructure (Tiffin and Irz, 2006). Nevertheless, the overall empirical literature has yielded mixed and sometimes conflicting evidence and there remains a lack of consensus on the effect of agriculture on economic growth. While a strand of the literature supports the presence of agricultural development as a precondition to industrialization and economic growth (Thirtle et al., 2003), another strand disagrees (Schiff and Valdez, 1998; Yao, 2000).

Given the above discussion, as well as the fact that the demand for this natural product is increasing on a global scale (Berthe et al., 2013; Legesse, 2014), this paper explores, for the first time, the contribution of the honey industry to economic growth. Honey has certain applications in related to sugar industries. In addition, the pharmaceutical industry has assigned certain healing benefits in relevance to honey, including drugs production and healthcare facilities, although its healing capacity seems to exert a negative impact on diabetic patients. Nevertheless, the medical use of honey is expected to expand furthermore, and, thus, to generate new businesses in the relevant manufacturing industry. According to Paterson (2006), the honey industry is a sustainable form of agriculture that can provide people, mostly in rural areas, with a source of much-needed income and nutrition and with advanced apicultural skills and equipment. The technological evolution associated with this industry is also substantially significant (Krell, 1996).

In terms of certain statistics associated with the global honey industry (available from http:/faostat.fao.org/site/339/default.aspx), the growth of global honey production seems to have concentrated on five major world regions: Latin America, North America, Europe, Asia-Pacific, and Middle East and Africa. More specifically, 
the major producers and exporters of honey are: Argentina, Mexico, Brazil, Canada, Uruguay, Chile, Cuba (the Americas group), China, India, Vietnam, Ukraine, Thailand, Taiwan and Turkey (the Eastern group) and Germany, Spain, Hungary, France, Belgium and Greece (the European group). Major honey exporting countries of the Americas showed a slight increase of their beehives counts since $2007(+3 \%)$, while their honey exports fell $9 \%$, probably due to the increased production difficulties for beekeeping in this region. By contrast, the total number of beehives of the Eastern group grew 13\%, while they increased their honey exports by $196 \%$. China, with 9 million beehives, it is by far the world's largest honey producer and exporter. Its annual honey production is around 450,000 tons and domestic consumption seems to be much larger than its production capacity. The Chinese consumer attributes important health benefits to this natural product. The gap between [consumption+ export] and [production + import] seems to be covered by dilution with syrups (Phipps, 2016). China has also been the number one honey exporter in the world, dominating $12 \%$ of the global honey sales. Germany has been the second largest producer and exporter followed by Mexico. Based on the merit of the honey industry for the overall economic performance of the economy of main producers and exporters, our study empirically investigates the association of the volume of honey production with economic growth by using a panel data set of the major global producers, spanning the period 1990-2016.

\section{Data and Methodology}

Annual data on the value of honey production, measured in US dollars, are obtained for Argentina, Mexico, Brazil, Canada, Uruguay, Chile, Cuba, China, India, Vietnam, Ukraine, Thailand, Taiwan and Turkey, spanning the period 1990-2016. Data were retrieved from the Food and Agriculture Organization of the United Nations. Annual data on real GDP (at 2010 constant prices) are obtained from Datastream and measured in US dollars. Moreover, based on both neoclassical and endogenous growth theories, the analysis considers a number of control variables that could drive economic growth, such as:

1. gross capital formation (Young, 1991),

2. the labor force (Azariadis and Drazen, 1990; Klenow and Rodriguez-Clare, 1997), measured as the total number of workers in the economy,

3. (secondary) school enrollment as a proxy for human capital (Rebelo, 1991),

4. budget deficits/surpluses as percentage of GDP (Barro, 1990; Gomez, 2007), and

5. trade openness (Frankel and Romer, 1999; Karras, 2008), measured as the ratio of the sum of imports and exports to GDP. Data on these controls are also obtained from Datastream.

In terms of methodology, the empirical part of the paper first, makes use of the cross-sectional dependence (CD) statistic by Pesaran (2004), which is based on a simple average of all pair-wise correlation coefficients of the OLS residuals obtained from standard augmented Dickey-Fuller regressions for each variable in the panel. Under the null hypothesis of cross-sectional independence, the $\mathrm{CD}$ test statistic follows asymptotically a two-tailed standard normal distribution. The CD test is given by:

$$
C D=\sqrt{[2 T / 2 N(N-1)]} \sqrt{\sum_{i=1}^{N-1} \sum_{j=i+1}^{N} \rho_{i j}}
$$

where $\mathrm{T}$ denotes the number of observations, $\mathrm{N}$ is the number of pairs and $\rho_{\mathrm{ij}}$ denotes the average of pair-wise correlation coefficients.

Next, the analysis makes use of a second-generation panel unit root test to determine the degree (order) of integration in the respective variables. The Pesaran (2007) panel unit root test (known also as "CIPS" test) does not require the estimation of factor loading to eliminate cross-sectional dependence. Specifically, the usual Dickey-Fuller regression is augmented to include the lagged cross-sectional mean and its first difference to capture the cross-sectional dependence that arises through a single-factor model. The null hypothesis is a unit root for the Pesaran (2007) test. The test yields:

$$
\operatorname{CIPS}(\mathrm{N}, \mathrm{T})=\frac{1}{N} \sum_{\mathrm{i}=1}^{\mathrm{N}} \mathrm{t}_{i}(\mathrm{~N}, \mathrm{~T})
$$

where $\mathrm{N}$ is again the number of pairs in the panel set and $\mathrm{T}$ denotes the number of observations, with $t_{i}(N, T)$ being the t-statistic of the OLS estimate of $\rho$, which is the correlation coefficient between the current and the lagged values in the Augmented Dickey-Fuller statistic.

In the next step, the empirical analysis considers the panel cointegration methodological approach to investigate the long-run equilibrium across the variables under study. Under the presence of cross-sectional dependence, the study makes use of the Durbin-Hausman test, recommended by Westerlund (2008), to explore the presence of cointegration. This test allows for cross-sectional dependence, modelled by a factor model in which the errors in the relevant regression are obtained by idiosyncratic innovations and unobservable factors that are common across units of the panel (Auteri and Constantini, 2005). The Durbin-Hausman test allows the stability ranks of the independent variables to be different, i.e. of any stationarity degree. Additionally, the test can be used only when the cross-sectional dependence is available. Two tests are calculated, i.e. one panel and one group. The panel statistics infer results for the panel in general, while the group statistics infer results for the individuals that make up the panel. In the Durbin-Hausman test, it is assumed that the residuals' ( $\mathrm{z}$ ) distribution adapted according to the equations below to allow for cross-sectional dependence:

$$
\begin{aligned}
& z_{i t}=\lambda^{\prime}{ }_{i} F_{t}+e_{i t} \\
& F_{j t}=p_{j} F_{t j-1}+u_{j t}
\end{aligned}
$$




$$
\mathrm{e}_{\mathrm{it}}=\varphi_{\mathrm{i}} \mathrm{e}_{\mathrm{it}-1}+\mathrm{v}_{\mathrm{it}}
$$

with $\mathrm{p}_{\mathrm{j}}<1$ for all js.

with $\mathrm{Ft}$ being the $\mathrm{k}$-sized vector of the $\mathrm{F}_{\mathrm{jt}}$ common factor and $\lambda_{i}$ being the vector of factor loadings. To generate the Durbin-Hausman test, the difference of the $z_{i t}$ equation is taken: $\Delta \mathrm{z}_{\mathrm{it}}=\lambda{ }^{\prime}{ }_{\mathrm{i}} \Delta \mathrm{F}_{\mathrm{t}}+\Delta \mathrm{e}_{\mathrm{it}}$. Given that $\Delta \mathrm{z}_{\mathrm{it}}$ is unknown, a principal component estimator must be used. The $\mathrm{z}_{\mathrm{it}}$ equation principal component can be written as:

$$
\Delta \mathrm{z}_{\mathrm{it}}=\Delta \mathrm{y}_{\mathrm{it}}-\beta_{\mathrm{i}} \Delta \mathrm{x}_{\mathrm{it}}
$$

which represent the residuals from the cointegrating vector. The $\Delta \mathrm{F}_{\mathrm{t}}$, which is the principal component estimator, can be obtained by calculating the eigenvector $\sqrt{ } \mathrm{T}-1$ times among the greatest eigen value of the $(\mathrm{T}-1)(\mathrm{T}-1)$ matrix, with $\lambda$ being calculated as: $\Delta \mathrm{F}^{\prime} \Delta \mathrm{z} /(\mathrm{T}-1)$. The null hypothesis, which expresses that there is no co-integration is the asymptotic equation that tests whether $\varphi_{i}=1$ in the regression: $e_{i t}=\varphi_{i} e_{i t-1}$ + error. After these calculations, the Durbin-Hausman test is calculated with the two versions of the formula below:

$$
\mathrm{DH}_{\mathrm{g}}=\sum_{\mathrm{i}=1}^{\mathrm{n}} \mathrm{S}_{i}\left(\varphi_{1 \mathrm{i}}-\varphi_{i}\right) \sum_{\mathrm{t}=2}^{\mathrm{T}} \mathrm{e}_{\mathrm{it}-1}
$$

and

$$
\mathrm{DH}_{p}=\left(\varphi_{1 \mathrm{i}}-\varphi_{i}\right)^{2} \sum_{\mathrm{i}=1}^{\mathrm{n}} \sum_{\mathrm{t}=2}^{\mathrm{T}} \mathrm{e}_{\mathrm{it}-1}
$$

where $\mathrm{DH}_{\mathrm{p}}$ expresses the panel statistic and $\mathrm{DH}_{\mathrm{g}}$ expresses the group statistic, respectively.

Finally, the analysis applies a panel methodology which takes into account cross-section and time dimensions of the data, as well as cross dependence, to estimate the long run relationship under consideration. When the errors of a panel regression are cross-sectionally correlated then standard estimation methods can lead to inconsistent estimates and incorrect inference (Phillips and Sul, 2003). In order to take into account the cross-sectional dependence we implement a novel econometric methodology, namely, the Common Correlated Effects (CCE) by Pesaran (2006). He suggests a new approach to estimation that takes into account cross sectional dependence. The proposed methodology allows individual specific errors to be serially correlated and heteroskedastic. In a series of Monte Carlo experiments, Pesaran (2006) and Kapetanios et al. (2011) show that the CCE estimators have the correct size, and in general have better small-sample properties than alternatives that are available in the literature. Furthermore, they have shown that small-sample properties of the CCE estimators do not seem to be much affected by the residual serial correlation of the errors. To obtain the long-run estimates, Pesaran (2006) adopts a multifactor residual model, such as:

$$
\begin{gathered}
y_{i t}=\alpha_{i}+\beta_{i} x_{i t}+\varepsilon_{i t} \\
\varepsilon_{i t}=\lambda^{\prime}{ }_{i} F_{t}+u_{i t}
\end{gathered}
$$

where subscript it is the ith cross section observation at time $t$, for $t=1,2, \ldots, T$ and $i=1,2, \ldots, N$. $F_{t}$ is the $m x 1$ vector of unobserved common factors. Pesaran (2006) considers the case of weakly stationary factors. However, Kapetanios et al. (2011) show that Pesaran's CCE approach continues to yield consistent estimation and valid inference even when common factors are unit root processes (I(1)). To deal with the residual cross section dependence Pesaran (2006) uses cross sectional averages, which can be consistently estimated within the following auxiliary regression:

$$
y_{i t}=\alpha_{j}+\beta_{j} x_{i t}+e_{i t}
$$

with a bar denoting the average value. Pesaran (2006) refers to the resulting OLS estimators $\hat{B}_{j, C C E}$ of the individual specific slope coefficients $B_{j}=(\beta)^{\prime}$, as the 'Common Correlated Effect' (CCE) estimators:

$$
\widehat{B}_{j, C C E}=\left(X_{j}^{\prime} \bar{D} X_{j}\right) X_{j}^{\prime} \bar{D} E_{j},
$$

where: $X_{j}=\left(x_{j 1}, x_{j 2}, \ldots, x_{j T}\right)^{\prime}, \quad x_{j t}=\left(Y_{j t}, Y_{j T}^{2}\right)^{\prime}, \quad E_{j}=$ $\left(E_{j 1}, E_{j 2}, \ldots, E_{j T}\right)^{\prime} \quad, \quad \bar{D}=I_{T}-\bar{H}\left(\bar{H}^{\prime} \bar{H}\right)^{-1} \bar{H} \quad, \quad \bar{H}=$ $\left(h_{1}, h_{2}, \ldots, h_{T}\right)^{\prime}$, and $\mathrm{h}_{\mathrm{t}}=\left(1, \mathrm{y}_{\mathrm{t}}, \mathrm{x}_{\mathrm{t}}\right)$ as the 'Common Correlated Effect' (CCE) estimators. The 'Common Correlated Effects Mean Group' (CCEMG) estimator is the average of the individual CCE estimators $\hat{B}_{j, C C E}$ :

$$
\hat{B}_{C C E M G}=\sum_{j=1}^{N} \hat{B}_{j, C C E}
$$

The new CCEMG estimator follows asymptotically the standard normal distribution. Specifically:

$$
\sqrt{N}\left(\hat{B}_{C C E M G}-B\right) \stackrel{d}{\longrightarrow} N\left(0, \Sigma_{M G}\right)
$$

In a series of Monte Carlo experiments, Pesaran (2006) and Kapetanios et al. (2011) show that the CCE estimators have the correct size, and in general have better small-sample properties than alternatives that are available in the literature. Furthermore, they have shown that small-sample properties of the CCE estimators do not seem to be much affected by the residual serial correlation of the errors.

\section{Results and Discussion}

In the first step of empirical analysis, we examine the unit root properties in the data through advanced panel unit root tests. Panel unit root tests of the first-generation can lead to spurious results (because of size distortions), if significant degrees of positive residual cross-section dependence exist and are ignored. Consequently, the implementation of second-generation panel unit root tests is desirable only when it has been established that the panel is subject to a significant degree of residual cross-section dependence. In the cases where cross-section dependence is not sufficiently high, a loss of power might result if second-generation panel unit root tests that allow for cross-section dependence are 
employed. Therefore, before selecting the appropriate panel unit root test, it is crucial to provide some evidence on the degree of residual cross-section dependence.

The results of the $\mathrm{CD}$ testing procedure are reported in Table 1 and they uniformly reject the null hypothesis of cross-section independence, providing evidence of crosssectional dependence in the data given the statistical significance of the CD statistics regardless of the number of lags (from 1 to 4 ) included in the ADF regressions.

Table 1. Cross Dependence Tests.

\begin{tabular}{lllll}
\hline Lags & \multicolumn{5}{l}{} \\
\hline Variables & $\mathbf{1}$ & $\mathbf{2}$ & $\mathbf{3}$ & $\mathbf{4}$ \\
\hline Honey production & {$[0.00]^{* * *}$} & {$[0.00]^{* * *}$} & {$[0.01]^{* * *}$} & {$[0.02]^{* *}$} \\
Real GDP & {$[0.00]^{* * *}$} & {$[0.00]^{* * *}$} & {$[0.00]^{* * *}$} & {$[0.00]^{* * *}$} \\
Labor force & {$[0.00]^{* * *}$} & {$[0.00]^{* * *}$} & {$[0.00]^{* * *}$} & {$[0.01]^{* * *}$} \\
Gross capital formation & {$[0.00]^{* * *}$} & {$[0.00]^{* * *}$} & {$[0.00]^{* * *}$} & {$[0.00]^{* * *}$} \\
School enrolment & {$[0.00]^{* * *}$} & {$[0.00]^{* * *}$} & {$[0.01]^{* * *}$} & {$[0.02]^{* *}$} \\
Public deficit & {$[0.00]^{* * *}$} & {$[0.00]^{* * *}$} & {$[0.00]^{* * *}$} & {$[0.00]^{* * *}$} \\
Trade openness & {$[0.00]^{* * *}$} & {$[0.00]^{* * *}$} & {$[0.00]^{* * *}$} & {$[0.01]^{* * *}$} \\
\hline
\end{tabular}

Notes: Under the null hypothesis of cross-sectional independence the CD statistic is distributed as a two-tailed standard normal. Results are based on the test of Pesaran (2004). Figures in parentheses denote p-values. $* * *: \mathrm{p} \leq 0.01, * *: \mathrm{p} \leq 0.05$.

Next, the results of the panel unit root test are reported in Table 2 and support the presence of a unit root in both variables under consideration. In other words, our sample variables are integrated of order one $\mathrm{I}(1)$.

Table 2. Panel Unit Root Tests.

\begin{tabular}{lll}
\hline Variable & Pesaran (CIPS) & Pesaran (CIPS*) \\
\hline Honey production & -1.33 & -1.42 \\
$\Delta$ Honey production & $-6.19^{* * *}$ & $-6.38^{* * *}$ \\
Real GDP & -1.29 & -1.45 \\
$\Delta$ real GDP & $-6.38^{* * *}$ & $-6.64^{* * *}$ \\
Labor force & -1.25 & -1.36 \\
$\Delta$ labor force & $-6.33^{* * *}$ & $-6.45^{* * *}$ \\
Gross capital formation & -1.30 & -1.42 \\
$\Delta$ gross capital formation & $-6.24^{* * *}$ & $-6.35^{* * *}$ \\
Public deficit & -1.31 & -1.39 \\
$\Delta$ public deficit & $-6.28^{* * *}$ & $-6.36^{* * *}$ \\
School enrollment & -1.38 & -1.45 \\
$\Delta$ school enrollment & $-5.95^{* * *}$ & $-6.17^{* * *}$ \\
Trade openness & -1.31 & -1.44 \\
$\Delta$ Trade openness & $-5.71^{* * *}$ & $-6.09^{* * *}$ \\
\hline
\end{tabular}

Notes: $\Delta$ denotes first differences. A constant is included in the Pesaran (2007) tests. Rejection of the null hypothesis indicates stationarity in at least one country. CIPS* = truncated CIPS test. Critical values for the Pesaran (2007) test are -2.40 at $1 \%,-2.22$ at $5 \%$, and -2.14 at $10 \%$, respectively. The results are reported at lag $=4$. The null hypothesis is that of a unit root. ***: $\mathrm{p} \leq 0.01$.

The results of the panel cointegration tests are reported in Table 3. These findings clearly illustrate that the null hypothesis of no-cointegration is rejected at the $1 \%$ significance level for both tests, indicating that there exists a significant long-run equilibrium among economic growth, honey production, and the remaining control variables, such as labor force, gross capital formation, public deficit as percentage of GDP, secondary school enrolment, and trade openness in our countries sample.

Table 3. Westerlund's Cointegration Tests (Full Sample).

\begin{tabular}{|c|c|}
\hline $\begin{array}{l}\mathrm{DH}_{\mathrm{g}} \\
\mathrm{DH}_{\mathrm{p}}\end{array}$ & $\begin{array}{l}7.928[0.00]^{* * *} \\
9.652[0.00]^{* * *}\end{array}$ \\
\hline $\begin{array}{l}\text { Notes: } \\
\mathrm{IC}_{2}(\mathrm{~K}) \\
\text { bandw } \\
4(\mathrm{~T} / 10 \\
\text { indicat }\end{array}$ & $\begin{array}{l}\text { ckets. The criterion used in this paper is } \\
\text { r of factors }(\mathrm{K}) \text { set equal to } 5 \text {. For the } \\
\text { to represent the largest integer less than } \\
\text { ey and West (1994). ***: } \mathrm{p} \leq 0.01 \text { and } \\
\text { gration null hypothesis. }\end{array}$ \\
\hline
\end{tabular}

The results of the CCE (long-run) estimates are reported in Table 4, with the variables of real GDP, honey production, labor force, gross capital formation and secondary school enrolment being expressed in logarithms. The findings highlight a positive and statistically significant honey production effect, indicating that higher honey production by 1 percent leads to a 0.23 percent increase in real GDP. The remaining control variables seem to carry the expected theoretical sign in relevance to their impact on economic growth, while they are all statically significant.

Table 4. Common Correlated Effects (CCE) Long-Run Estimates: The Dependent Variable is Real Economic Growth (Full Sample).

\begin{tabular}{llll}
\hline variables & coefficient & t-statistic & p-value \\
\hline constant & 1.135 & 3.472 & 0.01 \\
honey production & 0.234 & 7.859 & 0.00 \\
labor force & 0.286 & 5.984 & 0.00 \\
gross capital formation & 0.527 & 6.810 & 0.00 \\
public deficit ratio & 0.472 & 6.473 & 0.00 \\
school enrolment & 0.486 & 6.915 & 0.00 \\
trade openness & 0.509 & 7.952 & 0.00 \\
Adjusted R-squared & 0.73 & & \\
\hline
\end{tabular}

In this part of the empirical analysis we explore the role of the geographic factor with respect to the economic growthhoney production nexus by splitting our country sample into the Americas, Eastern and European groups. Table 5 reports the three panel groups cointegration tests, where in all three cases the findings reject the null hypothesis of no cointegration.

Table 5. Westerlund's Cointegration Tests (Country Groups).

\begin{tabular}{ll}
\hline Americas group & \\
$\mathrm{DH}_{\mathrm{g}}$ & $6.256[0.00]^{* * *}$ \\
$\mathrm{DH}_{\mathrm{p}}$ & $8.274[0.00]^{* * *}$ \\
Eastern group & \\
$\mathrm{DH}_{\mathrm{g}}$ & $9.673[0.00]^{* * *}$ \\
$\mathrm{DH}_{\mathrm{p}}$ & $11.503[0.00]^{* * *}$ \\
European group & \\
$\mathrm{DH}_{\mathrm{g}}$ & $6.135[0.00]^{* * *}$ \\
$\mathrm{DH}_{\mathrm{p}}$ & $7.628[0.00]^{* * *}$ \\
\hline
\end{tabular}

Notes: p-values are reported in brackets. The criterion used in this paper is $\mathrm{IC}_{2}(\mathrm{~K})$ with the Maximum number of factors $(\mathrm{K})$ set equal to 5 . For the bandwidth selection, $\mathrm{M}$ was chosen to represent the largest integer less than $4(\mathrm{~T} / 100)^{2 / 9}$, as suggested by Newey and West (1994). ***: $\mathrm{p} \leq 0.01$ and indicates the rejection of no co-integration null hypothesis.

Finally, Table 6 offers the CCE panel estimates in relevance to the three groups. The new findings illustrate that although in all three groups the effect of honey production on 
economic growth turns out to be positive and statistically significant, the impact gets stronger in the case of the Eastern group, followed by the Americas and the European groups, with coefficient estimates $0.26,0.19$ and 0.17 , respectively. In terms of the remaining control variables of economic growth, their estimates retain the expected theoretical sign and effect on economic growth.

Table 6. Common Correlated Effects (CCE) Long-Run Estimates: Dependent Variable is Real Economic Growth (Country Groups).

\begin{tabular}{llll}
\hline Variables & $\begin{array}{l}\text { Americas } \\
\text { group }\end{array}$ & $\begin{array}{l}\text { Eastern } \\
\text { group }\end{array}$ & $\begin{array}{l}\text { European } \\
\text { group }\end{array}$ \\
\hline constant & 0.8561 .972 & 0.693 & \\
& {$[0.02]$} & {$[0.01]$} & {$[0.02]$} \\
honey production 0.193 & 0.261 & 0.171 & \\
& {$[0.00]$} & {$[0.00]$} & {$[0.00]$} \\
labor force & 0.227 & 0.315 & 0.259 \\
& {$[0.00]$} & {$[0.00]$} & {$[0.00]$} \\
gross capital formation & 0.591 & 0.362 & 0.415 \\
& {$[0.00]$} & {$[0.00]$} & {$[0.00]$} \\
public deficit ratio & 0.539 & 0.238 & 0.486 \\
& {$[0.00]$} & {$[0.00]$} & {$[0.00]$} \\
school enrolment & 0.593 & 0.438 & 0.488 \\
& {$[0.00]$} & {$[0.00]$} & {$[0.00]$} \\
trade openness & 0.391 & 0.584 & 0.424 \\
& {$[0.00]$} & {$[0.00]$} & {$[0.00]$} \\
Adjusted R-squared & 0.65 & 0.77 & 0.61 \\
\hline
\end{tabular}

Note: Figures in brackets denote p-values.

\section{Conclusion}

This study explored, for the first time, the roe of honey production in the process of economic growth, by employing data on both honey production and real GDP, as well as on a number of economic drivers of growth obtained from the major global producers and exporters. Panel methodological approached offered findings that highlighted the substantial and statically significant impact of honey production on economic growth. The results got stronger for the case of the Eastern group of producers and exporters, followed by those in the cases of the Americas and European groups, indicating the strong dynamics of the honey industry in the case of Eastern countries, in terms of investments and job creation in these countries.

Hence, the honey industry has the potential of giving people opportunities for reliable income generation either through exporting or through job creation. The sector could also have positive spillovers through the provision of major inputs for the development of allied industries, like the brewery and pharmaceutical industries and improve environmental conservation. There are prospects for the sector to complement other efforts to enhance people's standard of living. When effectively supported, the honey industry could be one of the pillars for reducing poverty and economic vulnerability, especially in low income countries or in low-income regions, a topic for which future research activities could be intensified.

\section{Acknowledgements}

The authors need to express their gratitude to both the referees and the Editor of this journal for their constructive comments and suggestions that enhanced the merit of this work. Needless to say the usual disclaimer applies.

\section{References}

[1] Azariadis, C., and Drazen, A. (1990) Threshold Externalities in Economic Development. Quarterly Journal of Economics, $105,501-526$

[2] Auteri, M., and Constantini, M. (2005) Intratemporal Substitution and Government Spending: Unit Root and Cointegration Tests in a Cross Section Correlated Panel. 17th Conference Paper, SocietaItaliana di economiapubblica, Pavia, Universita.

[3] Banks, J., and Marsden, T. (2000) Integrating AgriEnvironment Policy, Farming Systems and Rural Development in Wales. Sociologia Ruralis, 440, 438-466.

[4] Barro, R. J. (1990) Government Spending in a Simple Model of Endogenous Growth. Journal of Political Economy, 98, $103-125$.

[5] Berhe, M., Mirutse, G., Gebremedhin, B. 2013. Identifying beekeepers' adaptation strategies in response to climate change in Tigray, Ethiopia. Journal of Agricultural Research $2,155-159$.

[6] Byerlee D. (2000) Targeting Poverty Alleviation in Priority Setting for Agricultural Research. Food Policy, 25, 429-445.

[7] Duncan, C. M. (2005) Why Poverty Persists in Appalachia. Retrieved from: http://www.pbs.org/wgbh/pages/frontline/countryboys/reading s/duncan.html.

[8] Frankel, J., and Romer, D. (1999) Does Trade Cause Growth? American Economic Review, 89, 379-399.

[9] Gomez, M. A. (2007) Fiscal Policy, Congestion, and Endogenous Growth. Journal of Public Economic Theory, 10, 595-622.

[10] Kapetanios, G., Pesaran, M. H., and Yamagata, T. (2011) Panels with Non-Stationary Multifactor Error Structures. Journal of Econometrics, 160, 326-348.

[11] Karras, G. (2008) Trade Openness and Economic Growth: Can we Estimate the Precise Effect? Applied Econometrics and International Development, 3, 7-25.

[12] Klenow, P., and Rodriguez-Clare, A. (1997) Economic Growth, a Review Essay. Working Paper, University of Chicago.

[13] Krell, R. (1996) Value-Added Products from Beekeeping. FAO Agricultural Science Bulletin, 56-78.

[14] Legesse, G. Y. 2014. Beeswax production and marketing in Ethiopia: challenges in value chain. Agriculture, Forestry and Fisheries 3, 447-451.

[15] Paterson, P. D. (2006) The Tropical Agriculturalist: Beekeeping. Wageningen: Macmillan Publishers Limited. 
[16] Pesaran, M. H. (2007) A Simple Panel Unit Root Test in the Presence of Cross-Section Dependence. Journal of Applied Econometrics, 22, 265-312.

[17] Pesaran, M. H. (2006) Estimation and Inference in Large Heterogeneous Panels with a Multifactor Error Structure. Econometrica, 74, 967-1012.

[18] Pesaran, M. H. (2004) General Diagnostic Tests for Cross Section Dependence in Panels. Cambridge Working Papers in Economics, No. 435 and CESifo Working Paper, No. 1229.

[19] Phillips, P. C. B., and Sul, D. (2003) Dynamic Panel Estimation and Homogeneity Testing under Cross Section Dependence. The Econometrics Journal, 6, 217-259.

[20] Rebelo, S. (1991) Long-Run Policy Analysis and Long-Run Growth. Journal of Political Economy, 99, 500-512.

[21] Rephann, T. J. (2008) The Economic Impact of Agriculture and Forestry on the Commonwealth of Virginia. Working Paper, Weldon Cooper, Center for Public Service, University of Virginia.

[22] Rosenberger, R. S., Gebremedhin, T. G., and Hailu, Y. (2002) An Economic Analysis of Urbanization of Agricultural Land in West Virginia. Research Paper, No. 2002-8, Division of Resources Management, West Virginia University.

[23] Schiff, M., and Valdez, A. (1998) Agriculture and the Macroeconomy. In: Gardner, B., and Rausser, G. (Eds.), Handbook of Agricultural Economics. Amsterdam: Elsevier Science.

[24] Thirtle, C., Lin, L., and Piesse, J. (2003) The Impact of Research-Led Agricultural Productivity Growth on Poverty Reduction in Africa, Asia and Latin America. World Development, 31, 1959-1975.

[25] Tiffin, R., and Irz, X. (2006) Is Agriculture the Engine of Growth? Agricultural Economics, 35, 79-89.

[26] Westerlund, J., (2008) Panel Cointegration Tests of the Fisher Effect. Journal of Applied Econometrics, 23, 193-233.

[27] Yao, S., (2000) How Important is Agriculture in China's Economic Growth? Oxford Development Studies, 28, 33-49.

[28] Young, A. (1991) Learning by Doing and the Dynamic Effects of International Trade. Quarterly Journal of Economics, 106, 369-406. 